\title{
Preferences for mental health treatment for post-partum depression among new mothers
}

\author{
Meital Simhi", Orly Sarid and Julie Cwikel
}

\begin{abstract}
Background: The prevalence rate of postpartum depression (PPD) is 9 to $17 \%$ among mothers, with higher rates among low income and immigrant populations. Due to the negative effects of PPD symptoms on both the mother and baby, treating mothers with depression symptoms is of great importance. This study examined treatment preferences for PPD among Israeli mothers with and without PPD symptoms, specifically focusing on treatment centers, type of professional and mode of treatment, to help develop relevant policies to promote the health of mothers by reaching a deeper understanding of their preferences.

Methods: 1000 mothers who attended Maternal Child Health Clinics (MCHCs) in Israel for their infant's first medical exam participated in a cross-sectional survey.

Results: In this sample, $8.4 \%$ of the participants suffered from PPD. Mothers with PPD compared to those without symptoms had lower economic status, were more likely to be single, to be first-time mothers, have an unemployed partner and to have immigrated to Israel. Mothers with PPD preferred private mental health practice and community treatment centers by mental healthcare professionals. They also preferred group interventions and personal psychotherapy rather than technology-based interventions.

Conclusions: The study findings support the formulation of mother-sensitive health policies based on understanding mothers' preferences, and thus, help prepare treatment alternatives that will suit different groups of mothers with PPD, for the benefit of mothers, newborns, and families. Disseminating the results of this study among professionals as part of professional training, can promote appropriate treatment facilities and modes of care for mothers with PPD.
\end{abstract}

Keywords: Treatment preferences, Postpartum depression, Health policy, Mothers, Demography

\section{Background}

PPD is characterized by an inability to experience pleasure, anxiety symptoms, panic attacks, spontaneous crying, depressed mood, and sometimes accompanied by suicidal thoughts following the birth of an infant [1]. Epidemiological studies show that the prevalence of PPD among the general population in Western countries ranges between 9 and 17\% [2, 3]. Risk factors identified from earlier studies include motherhood at a young age $[4,5]$, low levels of

\footnotetext{
* Correspondence: osaadon@post.bgu.ac.il

Spitzer Department of Social Work and the Center for Women's Health

Studies and Promotion, Ben Gurion University of the Negev, POB 653, 84105 Beer Sheva, Israel
}

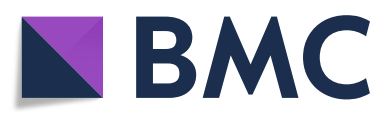

(c) The Author(s). 2019 Open Access This article is distributed under the terms of the Creative Commons Attribution 4.0 International License (http://creativecommons.org/licenses/by/4.0/), which permits unrestricted use, distribution, and reproduction in any medium, provided you give appropriate credit to the original author(s) and the source, provide a link to the Creative Commons license, and indicate if changes were made. The Creative Commons Public Domain Dedication waiver (http://creativecommons.org/publicdomain/zero/1.0/) applies to the data made available in this article, unless otherwise stated. education and SES $[6,7]$. A higher prevalence of PPD immigrant populations $[8,9]$.

Women who experience PPD often show signs of self-neglect and engage in risk-related behaviors such as the excessive consumption of alcohol, cigarettes, and illegal substances [5]. The newborn and the other family members can also be affected by the mother's PPD. Studies have reported that untreated PPD may adversely affect infant-maternal attachment [10], the cognitive and motor development of the infant $[10,11]$ and was associated with behavioral and learning disorders during childhood and adolescence [12, 13].

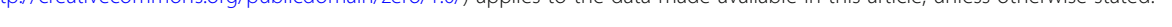


Due to the negative effects of PPD symptoms on both the mother and infant, early detection of women with PPD symptoms is of great public health importance. In many Western countries, a routine depression screening is performed among postpartum populations [14]. In Israel, since 2013, nurses routinely assess depressive symptoms during the 26-28th week of pregnancy and 4-9 weeks post-partum in perinatal health visits [15] using a validated translation of the Edinburgh Postnatal Depression Scale (EPDS) [16]. Despite the early detection of mothers with PPD, a large proportion of the mothers are not actually treated for their PPD symptoms [17, 18]. Moreover, results from a study conducted in Australia showed that $20 \%$ of women, when screened for perinatal depression and anxiety did not respond honestly. Women who felt uncomfortable reporting PPD symptoms were much more likely to show symptoms of perinatal depression and anxiety [19].

Currently, the treatments offered to women diagnosed with PPD are antidepressants [18]; psychodynamic therapy [20]; interpersonal therapy [21]; and cognitivebehavioral therapies [22], which have all been shown effective in treating PPD.

Previous studies that have examined preferences for treating PPD and showed variations in preferences for type of health care professionals, type of treatment and place of treatment, which differed according to the demographic profile of the mother. For example, a study conducted in the United States showed that compared to younger mothers, older mothers were more likely to seek therapy for their PPD symptoms [23]. Another study found that compared to Caucasian mothers African-American mothers preferred to receive counseling for their PPD symptoms from religious figures in the community and expressed low confidence in medication [24]. Findings from another study showed that educated, married women, with high SES, preferred individual psychotherapy rather than group therapy for their PPD symptoms [25].

Our study population included postpartum women who, according to previous studies [26], were expected to experience mild postpartum "baby blues" (between 60 and $80 \%$ of mothers), those who experienced clinical postpartum depression (around 15\% in most populations) and those who did not experience any symptoms of depression at all following childbirth. Thus, while it may be difficult to imagine how clinical depression feels, given that the vast majority of new mothers experience some symptoms, we ask them to speculate on what their preferences would be for treatment, given clinical post-partum depression. To the best of our knowledge, no previous studies have compared mothers with and without detected PPD as for their preferences for mental health treatment since it is clear that some women without reported or detected symptoms are still in need of effective and suitable PPD treatment. This was the rationale for the current study.

Our aim was to compare preferences for mental health treatment regarding a variety of mode, profession and place of treatment of mothers with and without PPD. We hypothesized that demographic variables will differ between mothers with and without PPD; we also hypothesized that mothers with PPD compared to those without symptoms would differ as to type of treatments preferences.

\section{Procedure}

A cross sectional study was conducted between December 2014 and August 2015 in eight Maternal and Child Health Clinics (MCHCs) in the center of Israel. The study population included 1000 mothers who attended the MCHCs for the first medical exam of their infant at nine weeks postpartum. Inclusion criteria were Hebrew-speaking mothers who gave birth to a child within the last six months and lived in the region. The study was approved by the research ethics committee of the Ministry of Health, Israel. The sample size was calculated using OpenEpi software for a two-sided significance level of 0.05 and statistical power of $80 \%$. OpenEpi indicated that 900 women were required for the study, which we increased to 1000 as we assumed that approximately $10 \%$ would not be fully compatible or would not provide complete data.

We approached mothers who came to MCHCs and presented the purpose of the study. If a mother met the inclusion criteria she was invited to participate. Out of the 1107 eligible mothers 1000 mother (90.2\%) agreed to participate, signed informed consent and completed the questionnaire; $7.5 \%$ (83) refused to participate and $2.3 \%$ [24] had missing data and were not included in the final analysis. Mothers, who were identified as having PPD symptoms, were advised to turn to treatment and were given details about where to access treatment in the vicinity of their residence.

\section{Study measures}

PPD symptoms were assessed using the Edinburgh Postnatal Depression Scale (EPDS) [16]. The questionnaire includes 10 questions, focusing on the feelings of mothers during the perinatal period. Each question is rated on a 4-point Likert scale. The tenth question is about intention to self-harm [27]. The score is the sum of all the statements. In this study, 
the cut-off point of 10 was selected, similar to previous studies conducted in Israel and in various countries $[3,7,8]$. The internal reliability was good (Cronbach $\alpha=0.82$ ).

Preferences for getting mental health treatment for PPD. The questionnaire was adapted from a previous study to reflect the treatment options available in Israel $[25,28]$.

a. Preferred place of treatment: mothers were asked, "If you felt depressed after birth, to which treatment center would you prefer to go?" Answers were eight different options, for example: $\mathrm{MCHCs}$, Community health clinic (Health Maintenance Organizations, HMOs), psychiatric clinic, or private mental health practice.

b. Health Care provider preference: mothers were asked, "If you felt depressed after childbirth, to what extent you would prefer the treatment of the following professionals?" Answers were twelve options, for example: nurses, social workers, or psychiatrist.

c. Preference regarding options to receive the therapy: mothers were asked "There are many ways to get treatment. To what extent do you feel that the following options would be suitable for your needs?" Fifteen options were presented, for example: home visits, Skype-based treatment, or group meetings.

d. Behavioral intent to access treatment in general was examined with one statement: "If you felt depressed after childbirth, would you go for treatment?" The participant responded on a four point Likert scale ranging from [1] very likely to go for treatment to [4] would not go for treatment at all.

Social-demographic questionnaire: age, ethnicity, years of education, economic status, religion, marital status, number of children, and the employment status of the mother and her husband.

\section{Sample}

In Table 1, we present socio-demographic variables of mothers with and without PPD. Mothers with PPD compared to those without symptoms had statistically significant lower economic status, were more likely to be single, to be first-time mothers, have an unemployed partner and to have immigrated to Israel.

\section{Data analysis}

The data was analyzed using SPSS version 23.0 software. We conducted $X^{2}$ and student t-tests with
Table 1 Demographic variables among women with and without PPD (Percentage (n))

\begin{tabular}{|c|c|c|c|}
\hline & With PPD & Without PPD & $x^{2}(d f)$ \\
\hline \multicolumn{4}{|l|}{ Marital status } \\
\hline Single & $18.2(4)$ & $81.8(18)$ & \multirow[t]{3}{*}{$6.97^{*}[2]$} \\
\hline Married & $7.9(76)$ & $92.1(883)$ & \\
\hline Live with a partner & $21.1(4)$ & $78.9(15)$ & \\
\hline \multicolumn{4}{|l|}{ Number of children } \\
\hline First child & $12.0(46)$ & $88.0(337)$ & \multirow[t]{2}{*}{$10.90^{* *}[1]$} \\
\hline Second child and up & $6.1(37)$ & $93.9(574)$ & \\
\hline \multicolumn{4}{|l|}{ Religion status } \\
\hline Secular & $8.6(40)$ & $91.4(427)$ & \multirow[t]{4}{*}{$0.64(3)$} \\
\hline Traditional & $9.2(25)$ & $90.8(248)$ & \\
\hline Religious & $7.5(12)$ & $92.5(148)$ & \\
\hline Ultra-Orthodox & $7.0(7)$ & $93.0(93)$ & \\
\hline \multicolumn{4}{|l|}{ Immigration } \\
\hline Immigrant & $12.4(29)$ & $87.6(205)$ & \multirow[t]{2}{*}{$6.33^{*}[1]$} \\
\hline Native born & $7.2(55)$ & $92.8(711)$ & \\
\hline \multicolumn{4}{|l|}{ Spouse unemployment } \\
\hline Unemployed spouse & $16.9(10)$ & $83.1(49)$ & \multirow[t]{2}{*}{$10.17^{*}[1]$} \\
\hline Working spouse & $7.6(70)$ & $92.4(856)$ & \\
\hline \multicolumn{4}{|l|}{ Economic status } \\
\hline Difficulty & $14.9(28)$ & $85.1(160)$ & \multirow[t]{3}{*}{$12.68^{* * *}[1]$} \\
\hline No difficulty & $6.9(56)$ & $93.1(756)$ & \\
\hline TOTAL IN THE SAMPLE & $8.4(84)$ & $91.6(916)$ & \\
\hline
\end{tabular}

${ }^{*} p \leq 0.05 ;{ }^{* *} p \leq 0.01 ;{ }^{* * *} p \leq 0.001$

demographic, and treatment preference variables among mothers with and without PPD in order to identify salient variables affecting treatment preferences. In the second stage of analysis, we preformed Exploratory Factor Analysis (EFA (for the three types of treatment preferences. Variables were included in the analysis, if their loading was .40 and above. We then conducted student t-tests with treatment preference variables after EFA comparing mothers with and without PPD.

\section{Results}

Among our participants $8.4 \%$ scored 10 or higher on EPDS. Ten (1\%) mothers stated in response to question 10 that they considered hurting themselves.

In Table 2 we present treatment preferences among mothers with PPD compared to those without symptoms. The top three preferred places among mothers with PPD were private mental health practice [1], community health clinic (HMOs) [2], and MCHCs [3]. Mother with PPD ranked community treatment centers 
Table 2 Treatment preferences by PPD status (means, standard deviations, t test)

\begin{tabular}{|c|c|c|c|c|c|}
\hline & $\begin{array}{l}\text { With PPD } \\
\text { Mean (SD) }\end{array}$ & $\begin{array}{l}\text { Degree of } \\
\text { preference }\end{array}$ & $\begin{array}{l}\text { Without PPD } \\
\text { Mean (SD) }\end{array}$ & $\begin{array}{l}\text { Degree of } \\
\text { preference }\end{array}$ & $\begin{array}{l}t(d f= \\
998)\end{array}$ \\
\hline \multicolumn{6}{|l|}{ Treatment centers } \\
\hline Private mental health practice & $2.55(1.26)$ & 1 & $2.51(1.26)$ & 2 & 0.30 \\
\hline Community health clinic (HMOs) & $2.38(1.04)$ & 2 & $2.70(1.11)$ & 1 & $-2.55^{*}$ \\
\hline $\mathrm{MCHCS}$ & $2.26(1.05)$ & 3 & $2.49(1.12)$ & 3 & -1.81 \\
\hline Mental health clinics for women in general hospitals & $2.10(1.13)$ & 4 & $2.09(1.13)$ & 4 & 0.11 \\
\hline Community mental health centers & $1.84(1.03)$ & 5 & $1.78(0.99)$ & 6 & .51 \\
\hline General hospital outpatient clinic & $1.75(0.92)$ & 6 & $1.81(0.99)$ & 5 & 0.13 \\
\hline Psychiatric hospital outpatient clinic & $1.60(0.95)$ & 7 & $1.52(0.88)$ & 7 & 0.84 \\
\hline Inpatient in a psychiatric hospital & $1.17(0.54)$ & 8 & $1.21(0.60)$ & 8 & -0.59 \\
\hline \multicolumn{6}{|l|}{ Type of professional } \\
\hline Psychologist & $3.54(1.49)$ & 1 & $3.49(1.41)$ & 1 & 0.37 \\
\hline Alternative therapist (shiatsu, massage, acupuncture) & $3.17(1.52)$ & 2 & $2.88(1.52)$ & 3 & 1.66 \\
\hline Family Physician & $2.79(1.37)$ & 3 & $2.98(1.40)$ & 2 & -1.16 \\
\hline A family member, friend or co-worker & $2.77(1.40)$ & 4 & $2.60(1.45)$ & 4 & 1.00 \\
\hline Psychiatrist & $2.52(1.51)$ & 5 & $2.42(1.43)$ & 8 & .58 \\
\hline Art/ Movement/ Music therapist & $2.32(1.46)$ & 6 & $2.51(1.52)$ & 6 & -1.10 \\
\hline Social Worker & $2.30(1.37)$ & 7 & $2.55(1.38)$ & 5 & -1.52 \\
\hline Nurse & $2.23(1.21)$ & 8 & $2.49(1.36)$ & 7 & -1.67 \\
\hline Occupational Therapist & $2.17(1.44)$ & 9 & $2.30(1.39)$ & 9 & -.82 \\
\hline A volunteer trained for this purpose & $2.08(1.37)$ & 10 & $2.23(1.37)$ & 10 & -.93 \\
\hline Religious leaders & $1.95(1.43)$ & 11 & $1.88(1.35)$ & 11 & .47 \\
\hline \multicolumn{6}{|l|}{ Mode of treatment } \\
\hline Personal meetings in a private office & $2.94(1.07)$ & 1 & $3.07(1.03)$ & 1 & -1.10 \\
\hline Home visits & $2.59(1.20)$ & 2 & $2.61(1.21)$ & 3 & -.11 \\
\hline Group meetings in the community led by a professional & $2.48(1.06)$ & 3 & $2.27(1.12)$ & 4 & 1.65 \\
\hline Personal psychotherapy in a community clinic & $2.45(1.04)$ & 4 & $2.67(1.08)$ & 2 & -1.84 \\
\hline $\begin{array}{l}\text { Group meetings community led by a woman who is not a professional } \\
\text { but has experienced similar problems }\end{array}$ & $2.07(1.06)$ & 5 & $1.99(1.06)$ & 5 & .60 \\
\hline Internet-based treatment, chatting with another woman in my situation & $1.96(1.05)$ & 6 & $1.93(1.04)$ & 6 & -.13 \\
\hline Treatment by phone & $1.89(1.04)$ & 7 & $1.87(1.06)$ & 7 & .13 \\
\hline Medications and treatment & $1.80(1.04)$ & 8 & $1.87(1.04)$ & 8 & .84 \\
\hline Internet-based treatment, chatting with a professional & $1.63(.95)$ & 9 & $1.64(0.94)$ & 11 & -.15 \\
\hline Practice on a website with the help and explanation of therapist & $1.58(.94)$ & 10 & $1.68(0.96)$ & 10 & -92 \\
\hline Using an iPhone application & $1.51(.82)$ & 11 & $1.70(1.01)$ & 9 & -1.69 \\
\hline Skype with a professional & $1.47(.84)$ & 12 & $1.53(.91)$ & 12 & -.54 \\
\hline Medication & $1.47(.89)$ & 12 & $1.39(0.77)$ & 13 & .95 \\
\hline $\begin{array}{l}\text { Group meetings on the web with women with the same problems as a } \\
\text { self-help group }\end{array}$ & $1.39(.87)$ & 13 & $1.35(0.77)$ & 14 & .52 \\
\hline Would seek treatment in general & $3.04(1.12)$ & & $3.29(1.00)$ & & $-2.12^{*}$ \\
\hline
\end{tabular}

in second place compared with women without PPD who ranked it first $(\mathrm{t}(998)=-2.55, p \leq 0.05$.

The preferred professionals were psychologists [1], alternative therapists [2], and family physicians [3]. The top three preferred services among women with PPD were personal meetings in a private office [1], home visits [2], and group meetings in the community under the guidance of a professional [3]. 
It is important to note that mothers with PPD also were less likely to seek treatment in general $(\mathrm{t}$ $(998)=-2.12, p \leq 0.05)$. No statistically significant differences were found for the other preferences.

In the second stage, of analysis we preformed EFA for all forms of treatment preferences to examine whether the number of components in each preference could be reduced. The analysis showed three main factors in each type of preference. a. Place of treatment: community health clinic; psychiatric clinics; and private mental health practice (Appendix 1). b. Professionals: professionals in the community; mental health professionals; and paraprofessionals in the community (Appendix 2). c. Mode of treatment: personal psychotherapy; technology-mediated interventions; and group interventions (Appendix 3).

In Table 3, we present treatment preferences after the EFA among mothers with PPD compared to those without symptoms. Differences were found between mothers with and without PPD regarding preferences for community treatment centers. Mother with PPD ranked community treatment centers in second place compared with women without PPD who ranked it first $(\mathrm{t} \quad(998)=-2.71$, $p \leq 0.01)$. No statistically significant differences were found for the other preferences. Mothers with PPD and mothers without PPD preferred private mental health practice (Ranking 1 and 2 respectively) and community treatment centers (Ranking 2 and 1 respectively) and were less likely to want to seek treatment in a psychiatric framework. They also preferred mental health care professionals, group interventions and personal psychotherapy interventions and not technologically mediated interventions.

\section{Discussion}

This study examined comparatively preferences to psychological treatment of mothers with and without PPD. In terms of PPD symptoms, $8.4 \%$ of the participants scored 10 or higher. This finding is in accordance with findings of previous studies conducted in Israel among Jewish mothers reporting 9\% at cut off point of 10 [8]. While the response rate in our study was high [29], there are still populations that were not represented in this sample, such as Arabicspeaking women whose rates of PPD have been reported as significantly higher than the rest of the population [8].

Our findings showed that women who immigrated to Israel were more likely to suffer from PPD than Israeli-born women. These findings are consistent with previous studies showing immigration as a risk factor for PPD [7, 9]. Women living with a partner had more symptoms of PPD than single or married women. This finding is supported by findings from previous studies [4, 17]. As in other studies we showed that women with poor economic status had more PPD symptoms [4, 30] and preferred to seek treatment less frequently in general [25]. Another finding was that mothers with a first child reported of more symptoms of PPD than mothers with second child and above. The findings in the literature are inconclusive regarding this topic. On the one hand, previous research has shown that women with a first child have more PPD symptoms than women with a second child [31]. However, another study showed a positive correlation between the number of children and PPD [32]. In other studies, however, there was no association between these variables [17, 33].

Table 3 Treatment preferences after Exploratory Factor Analysis by PPD status (means, standard deviations, t test)

\begin{tabular}{|c|c|c|c|c|c|}
\hline & PPD mean (SD) & Degree of preference & $\begin{array}{l}\text { Without PPD } \\
\text { mean (SD) }\end{array}$ & Degree of preference & $t(d f=998)$ \\
\hline \multicolumn{6}{|l|}{ Treatment centers } \\
\hline Private mental health practice & $2.55(1.26)$ & 1 & $2.51(.90)$ & 2 & .30 \\
\hline Community treatment centers & $2.32(.84)$ & 2 & $2.59(0.90)$ & 1 & $-2.71^{* *}$ \\
\hline Psychiatric clinics & $1.69(.68)$ & 3 & $1.68(.70)$ & 3 & .10 \\
\hline \multicolumn{6}{|l|}{ Type of professional } \\
\hline Mental health professionals & $3.02(1.35)$ & 1 & $2.95(1.21)$ & 1 & .46 \\
\hline Professionals in the community & $2.44(.91)$ & 2 & $2.67(1.06)$ & 2 & -1.94 \\
\hline Paraprofessionals in the community & $2.42(1.05)$ & 3 & $2.48(1.11)$ & 3 & -.44 \\
\hline \multicolumn{6}{|l|}{ Mode of treatment } \\
\hline Group interventions & $2.27(.96)$ & 1 & $2.13(1.01)$ & 2 & 1.24 \\
\hline Personal psychotherapy & $2.25(.65)$ & 2 & $2.31(.63)$ & 1 & -.90 \\
\hline Technology mediated interventions & $1.62(.64)$ & 3 & $1.67(.67)$ & 3 & -.58 \\
\hline
\end{tabular}


In the current study, mothers with and without PPD preferred to be treated in private mental health practice and in community treatment centers. They least preferred the option of psychiatric clinics. These findings are consistent with the findings of a previous study conducted in the US. There $90 \%$ of mothers preferred to receive primary care in private mental health practice and about $70 \%$ preferred to receive primary care in primary care clinics. Only one-fifth of mothers preferred to be treated in mental health care [25]. A possible explanation for our finding is that mothers feared social labeling of mental illness and the stigma associated with being a patient in a psychiatric setting [17, 18, 34]. In Israel, outpatient mental health care services from psychiatric hospitals were transferred in 2015 to HMOs in the community. Among other things, this was done to reduce the labeling of those with mental illness and to facilitate integration into the community of people suffering from mental difficulties. Our study was conducted during the implementation of this policy by the Ministry of Health and our findings support the rationale behind this change.

We also found that mothers preferred to be treated by professionals such as psychologists and family physicians and gave a lower priority for informal professionals such as volunteers and alternative caregivers. These findings are supported by a previous research conducted in Israel showing that about one-third of mothers with PPD symptoms sought treatment from professionals [17].

Our findings showed that women with PPD preferred group interventions and personal psychotherapy, such personal meetings and home visits compared to technology-mediated interventions. This finding is interesting because, as suggested in previous studies, women preferred more personal psychotherapy $[20,24,25]$, and were less likely to prefer group interventions [25]. It is possible that group therapy enables mothers to develop better strategies for coping with PPD symptoms by learning from other mothers' experiences. Group interventions can give mothers a feeling that they are not alone but rather part of a group coping with difficulties of PPD [35]. Women were less likely to prefer technologically mediated interventions, although this type of treatment can reduce the labeling of mental illness and protect their privacy [36]. Future research is warranted to examine this finding. Our findings also reinforce other studies that showed that women are very unlikely to prefer medications for treatment of PPD, which was ranked $12 / 13[21,37,38]$.
We found that mothers with PPD compared to mothers without PPD were less likely to seek treatment in general. This finding was supported by previous studies in Israel and abroad [17, 18, 34]. It is possible that mothers with PPD may be afraid that seeking help for their symptoms will be construed as evidence of defective parenting capacity. Thus, the findings of previous studies have shown that fear of tagging as a "bad mother" reduced the reference to treat symptoms of PPD [39, 40]. It is also possible that mothers with PPD symptoms have less energy in general to move outside of their personal realm and initiate help seeking, which reinforces the need for identifying these mothers and bringing treatment to them, through home visits or other means.

It is important to identify the factors that hinder accessing treatment among women with PPD. This behavior raises concerns and emphasizes the need for active reaching out to engage these mothers, to overcome their fear of excess stigmatization in the health and welfare care systems.

The primary limitation of this study is that it is cross-sectional and did not include Arabic-speaking mothers. Future studies should include the attitudes and behavioral intentions of other sectors of Israeli society as well.

\section{Conclusions}

Mothers with PPD represent a high-risk population who can benefit greatly from appropriate treatment. Our findings show that mothers with PPD have unique preferences. Mothers with PPD preferred private mental health practice and community treatment centers by mental healthcare professionals, and preferred group interventions and personal psychotherapy rather than technology-based interventions. We also found that mothers with PPD compared to mothers without PPD were less likely to seek treatment in general.

On the practical level, sharing the findings of this study with professionals, such as nurses at family health centers or physicians, in professional training sessions, lectures, seminars and journals, can increase awareness of their role in providing formal support for mothers who require treatment for PPD.

Our findings may assist professionals to develop relevant policies and programs designed to promote the health of mothers by reaching a deeper understanding of their preferences. As a result, therapy alternatives can be developed to better suit diverse groups of mothers in Israel who cope with the impacts of PPD, for the benefit of mothers, children, and entire families. 


\section{Appendix 1}

Table 4 Preferred place of treatment (exploratory factor analysis)

\begin{tabular}{lccc}
\hline Place of treatment & $\begin{array}{c}\text { Community } \\
\text { health clinic }\end{array}$ & $\begin{array}{l}\text { Psychiatric } \\
\text { clinics }\end{array}$ & $\begin{array}{l}\text { Private mental } \\
\text { health practice }\end{array}$ \\
\hline MCHCs & .80 & \\
$\begin{array}{l}\text { Community health clinic } \\
\text { (HMOs) }\end{array}$ & .69 & \\
$\begin{array}{l}\text { Community mental health } \\
\text { centers }\end{array}$ & .72 \\
$\begin{array}{l}\text { Psychiatric hospital outpatient } \\
\text { linic }\end{array}$ & .84 \\
$\begin{array}{l}\text { General hospital outpatient } \\
\text { clinic }\end{array}$ & \\
$\begin{array}{l}\text { Mental health clinics for } \\
\text { women in general hospitals }\end{array}$ & .77 \\
$\begin{array}{l}\text { Inpatient in a psychiatric } \\
\text { hospital } \\
\text { private mental health practice }\end{array}$ & .73 \\
\hline
\end{tabular}

\section{Appendix 2}

Table 5 Preferred type of professional (exploratory factor analysis)

\begin{tabular}{lccc}
\hline Type of professional & $\begin{array}{c}\text { Professional in } \\
\text { the community }\end{array}$ & $\begin{array}{c}\text { Mental health } \\
\text { professionals }\end{array}$ & $\begin{array}{c}\text { Allied health } \\
\text { workers }\end{array}$ \\
\hline Nurse & .54 & & \\
Social Worker & .46 & & \\
Family Doctor & .60 & .69 & .66 \\
Psychiatrist & & .73 & .68 \\
Psychologist & & .66 \\
A volunteer trained for \\
this purpose \\
Occupational therapist \\
Alternative therapist \\
$\begin{array}{l}\text { Art/ Movement/ Music } \\
\text { therapist }\end{array}$ & & .71 \\
\hline
\end{tabular}

\section{Appendix 3}

Table 6 Preferred mode of treatment (exploratory factor analysis)

\begin{tabular}{llll}
\hline Mode of treatment & $\begin{array}{l}\text { Personal } \\
\text { based } \\
\text { interventions }\end{array}$ & $\begin{array}{l}\text { Technology } \\
\text { mediated } \\
\text { interventions }\end{array}$ & $\begin{array}{l}\text { Group based } \\
\text { interventions }\end{array}$ \\
\hline
\end{tabular}

Home visits $\quad .49$

Personal meetings in the $\quad .44$

community clinic

Personal meetings in a $\quad .55$

private office

Medications

Medications and treatment

.72
Treatment by phone

Skype with a professional

Internet-based treatment,

chatting with a professional

Internet-based treatment,

chatting with another

woman in my situation

Group meetings on the web with women with the

same problems as a self-

help group

Practice on a computer site with help and explanation

of therapist, online

Using an iPhone application

Group meetings in the

community under the

guidance of a professional

Group meetings community

under the guidance of a

woman who is not a

professional but has

experienced similar

problems
.60

.49
.44
.55
.62
.72

.75

.77

.70

.66

.62

\section{Abbreviations}

EFA: Exploratory Factor Analysis; HMOs: Health Maintenance Organizations; MCHCs: Maternal Child Health Clinics; PPD: Post-partum depression

\section{Acknowledgements}

The authors wish to thank Ms. Saralee Glasser for her consultation on the grant, to Dr. Ofra Havkin, Dr. Marina Polyakov, and Ms. Gila Stern for their collaboration in fielding the study and to the mothers who participated. The authors also wish to thank The Israeli Scholarship Education Foundation (ISEF) for PhD excellence in academic and social leadership (to M.S) for their support.

\section{Authors' contributions}

MS performed the study and statistical analyses. She also contributed to the interpretation of the data and was a major contributor in OS was a major contributor in planning the research, conducted the statistical analyses and contributed to the interpretation of data, and writing of the manuscript. JC was a major contributor in planning the research, the interpretation of the data, and writing the manuscript. All authors read and approved the final manuscript. 


\section{Funding}

This research was supported by Grant 46/2013/R from the Israel National Institute for Health Services Research.

\section{Availability of data and materials}

The datasets used and/or analyzed during the current study are available from the corresponding author on reasonable request.

\section{Ethics approval and consent to participate}

All procedures performed in studies involving human participants were in accordance with the ethical standards of the institutional and/or national research committee (The Ministry of Health, 13/46) and with the 1964 Helsinki declaration and its later amendments or comparable ethical standards.

This article does not contain any studies with animals performed by any of the authors.

\section{Consent for publication}

Not applicable.

\section{Competing interests}

The authors declare that they have no competing interests.

Received: 2 July 2019 Accepted: 28 November 2019

Published online: 05 December 2019

\section{References}

1. American Psychiatric Association. Diagnostic and statistical manual of mental disorders: DSM-5. American Psychiatric Pub. 2013.

2. Robertson E, Grace $S$, Wallington T, Stewart DE. Antenatal risk factors for postpartum depression: a synthesis of recent literature. Gen Hosp Psychiatry. 2004;26(4):289-95.

3. Yelland J, Sutherland G, Brown SJ. Postpartum anxiety, depression and social health: findings from a population-based survey of Australian women. BMC Public Health. 2010;10(1):771.

4. Reck C, Struben K, Backenstrass M, Stefenelli U, Reinig K, Fuchs T, et al. Prevalence, onset and comorbidity of postpartum anxiety and depressive disorders. Acta Psychiatr Scand. 2008;118(6):459-68.

5. Wisner KL, Chambers C, Sit DKY. Postpartum depression: a major public health problem. J Am Med Assoc. 2006;296(21):2616-8.

6. Wisner KL, Sit DKY, McShea MC, Rizzo DM, Zoretich RA, Hughes $C L$, et al. Onset timing, thoughts of self-harm, and diagnoses in postpartum women with screen-positive depression findings. JAMA Psychiatry. 2013;70(5):49098.

7. Glasser S, Barell V, Boyko V, Ziv A, Lusky A, Shoham A, et al. Postpartum depression in an Israeli cohort: demographic, psychosocial and medical risk factors. J Psychosom Obstet Gynaecol. 2000;21(2):99-108.

8. Glasser S, Stoski E, Kneler V, Magnezi R. Postpartum depression among Israeli Bedouin women. Arch Womens Ment Health. 2011;14(3):203-8.

9. Dennis CLE, Janssen PA, Singer J. Identifying women at-risk for postpartum depression in the immediate postpartum period. Acta Psychiatr Scand. 2004;110(5):338-46.

10. Akman I, Kuşçu K, Özdemir N, Yurdakul Z, Solakoglu M, Orhan L, et al. Mothers' postpartum psychological adjustment and infantile colic. Arch Dis Child. 2006:91(5):417-9.

11. Patel V, DeSouza N, Rodrigues M. Postnatal depression and infant growth and development in low income countries: a cohort study from Goa, India. Arch Dis Child. 2003;88(1):34-7.

12. Diego MA, Field T, Hernandez-Reif M, Cullen C, Schanberg S, Kuhn C. Prepartum, postpartum, and chronic depression effects on newborns. Psychiatry. 2004;67(1):63-80.

13. Goodman JH. Paternal postpartum depression, its relationship to maternal postpartum depression, and implications for family health. J Adv Nurs. 2004; 45(1):26-35

14. Gjerdingen DK, Yawn BP. Postpartum Depression Screening: Importance, Methods, Barriers, and Recommendations for Practice. J Am Board Fam Med. 2007;20(3):280-8.

15. Ministry of Health. Procedure for Locating Women at Risk for Depression in Pregnancy and Postpartum, Public Health Services, No. 20/12. 2014.

16. Cox JL, Holden JM. Perinatal mental health: a guide to the Edinburgh postnata depression scale (EPDS). London: Royal College of Psychiatrists; 2003.
17. Bina R. Seeking help for postpartum depression in the Israeli Jewish Orthodox Community: factors associated with use of professional and informal help. Women Heal. 2014;54(5):455-73.

18. Horowitz JA, Cousins A. Postpartum Depression Treatment Rates for At-Risk Women. Nurs Res. 2006;55(2):S23-S27.

19. Forder PM, Rich J, Harris S, Chojenta C, Reilly N, Austin MP, et al. Honesty and comfort levels in mothers when screened for perinatal depression and anxiety. Women and Birth. 2019.

20. Cooper PJ, Murray L, Wilson A, Romaniuk H. Controlled trial of short and long term effect of psychological treatment of post partum depression. $\mathrm{Br} J$ Psychiatry. 2003;182(5):412-9.

21. O'Hara MW, Scott S, Gorman Laura L, Amy W. Efficacy of interpersonal psychotherapy for postpartum depression. Arch Gen Psychiatry. 2000;57(11): 1039-45.

22. Milgrom J, Holt CJ, Gemmill AW, Ericksen J, Leigh B, Buist A, et al. Treating postnatal depressive symptoms in primary care: a randomised controlled trial of GP management, with and without adjunctive counselling. BMC Psychiatry. 2011;11(1):95

23. McGarry J, Kim H, Sheng X, Egger M, Baksh L. Postpartum depression and help-seeking behavior. J Midwifery Women's Heal. 2009;54(1):50-6.

24. O'Mahen HA, Flynn HA. Preferences and perceived barriers to treatment for depression during the perinatal period. J Women's Heal. 2008:17(8):1301-9.

25. Goodman JH. Women's attitudes, preferences, and perceived barriers to treatment for perinatal depression. Birth. 2009;36(1):60-9.

26. Munoz C, Agruss J, Haeger A, Sivertsen L. Postpartum depression: Detection and treatment in the primary care setting. J Nurse Pract. 2006;2(4):247-53.

27. Glasser S, Barell V. Depression scale for research in and identification of postpartum depression. Harefuah. 1999:136(10):764-8.

28. Jimenez DE, Bartels SJ, Cardenas V, Dhaliwal SS, Alegría M. Cultural beliefs and mental health treatment preferences of ethnically diverse older adult consumers in primary care. Am J Geriatr Psychiatry. 2012;20(6):533-42.

29. Jardri R, Pelta J, Maron M, Thomas P, Delion P, Codaccioni X, et al. Predictive validation study of the Edinburgh Postnatal Depression Scale in the first week after delivery and risk analysis for postnatal depression. J Affect Disord. 2006:93(1-3):169-76.

30. Johnstone SJ, Boyce PM, Hickey AR, Morris-Yates AD, Harris MG. Obstetric risk factors for postnatal depression in urban and rural community samples. Aust N Z J Psychiatry. 2001;35(1):69-74.

31. Green K, Broome H, Mirabella J. Postnatal depression among mothers in the United Arab Emirates: socio-cultural and physical factors. Psychol Heal Med. 2006;11(4):425-31.

32. Forman DR, O'Hara MW, Stuart S, Gorman LL, Larsen KE, Coy KC. Effective treatment for postpartum depression is not sufficient to improve the developing mother-child relationship. Dev Psychopathol. 2007;19(2):585-602.

33. Eilat-Tsanani S, Merom A, Romano S, Reshef A, Lavi I, Tabenkin H. The effect of postpartum depression on womens' consultations with physicians. Isr Med Assoc J. 2006;8(6):406

34. Evins GG, Theofrastous JP, Galvin SL. Postpartum depression: a comparison of screening and routine clinical evaluation. Am J Obstet Gynecol. 2000;182(5):1080-2.

35. Scope A, Leaviss J, Kaltenthaler E, Parry G, Sutcliffe P, Bradburn M, et al. Is group cognitive behaviour therapy for postnatal depression evidence-based practice? A systematic review. BMC Psychiatry. 2013;13(1):321.

36. O'Mahen HA, Woodford J, McGinley J, Warren FC, Richards DA, Lynch TR, et al. Internet-based behavioral activation-Treatment for postnatal depression (Netmums): a randomized controlled trial. J Affect Disord. 2013; 150(3):814-22

37. Brandon, AR, Freeman M. When she says "no" to medication: psychotherapy for antepartum depression. Curr Psychiatry Rep. 2011;13(6):459-66.

38. Pearlstein TB, Zlotnick C, Battle CL, Stuart S, O'Hara MW, Price AB, et al. Patient choice of treatment for postpartum depression: a pilot study. Arch Womens Ment Health. 2006:9(6):303-8.

39. Wisner KL, Perel JM, Peindl KS, Hanusa BH, Piontek CM, Findling RL. Prevention of postpartum depression: a pilot randomized clinical trial. Am J Psychiatry. 2004;161(7):1290-2.

40. Wisner KL, Scholle SH, Stein B. Perinatal disorders: advancing public health opportunities. J Clin Psychiatry. 2008;69(10):1602-5.

\section{Publisher's Note}

Springer Nature remains neutral with regard to jurisdictional claims in published maps and institutional affiliations. 